\title{
GRADIENTE DE CONCENTRAÇÃO EM DISPOSITIVO MICROFLUÍDICO PARA OTIMIZAÇÃO DE BIOPROCESSOS
}

\author{
A. F.OLIVEIRA ${ }^{1}$, R. G. BASTOS ${ }^{2}$ e L. G. de LA TORRE ${ }^{1}$ \\ ${ }^{1}$ Universidade Estadual de Campinas, Departamento de Engenharia de Materiais e \\ Bioprocessos \\ ${ }^{2}$ Universidade Federal de São Carlos, Centro de Ciências Agrárias, Departamento de \\ Tecnologia Agroindustrial e Socioeconomia Rural \\ E-mail para contato: alinefurtado@feq.unicamp.br
}

\begin{abstract}
RESUMO -A microfluídica opera em microlitros, obtendo resultados rápidos num sistema precisamente controlado. Neste trabalho, foi projetado um dispositivo microfluídico gerador de gradiente de concentração puramente difusivo para investigar as condições ideais de crescimento microbiano. O dispositivo foi construído em base de vidro, com dois níveis: inferior, onde ocorre o gradiente difusivo e crescimento celular em microcanais e; superior, para o fluxo de soluções com concentrações diferentes. $\mathrm{O}$ comportamento da Saccharomyces cerevisiae ATCC 7754 foi avaliado em concentrações de 0 a $40 \mathrm{~g} / \mathrm{L}$ de glicose, numa vazão de $15 \mu \mathrm{l} / \mathrm{min}$, ambiente anaeróbio, $30{ }^{\circ} \mathrm{C}$, operado por $10 \mathrm{~h}$ em microscópio confocal e obtidas imagens a cada $30 \mathrm{~min}$. Nos microcanais notou-se o crescimento celular, com resultados correlacionados à fermentação convencional. Portanto, esta tecnologia é viável para a determinação de condições ideias para micro-organismos, sendo uma tecnologia mais simples e prática para otimização de bioprocessos.
\end{abstract}

\section{INTRODUÇÃO}

Microfluídica é uma ciência inovadora e que opera em escala micrométrica, utilizando pequenos volumes de amostras e reagentes que escoam por microcanais. A possibilidade de explorar o transporte de fluidos em pequenas dimensões e em regime laminar, permite o controle de moléculas no espaço e no tempo, além de mimetizar microambientes celulares (Whitesides, 2006; Schapperet al., 2009). Os dispositivos microfluídicos podem ser construídos com uma diversidade em geometrias que são aplicáveis para inúmeras áreas de pesquisas. Dentre as geometrias, a capacidade de formar gradientes de concentração permite avaliar condições favoráveis para o desempenho celular, e esta possibilidade tem sido usada principalmente em pesquisas com células animais (Tavana et al., 2008).

Ambientes microfluídicos com gradiente de concentração podem ser formados pela contribuição convectiva (ou advecção, com a presença de movimento do fluído) ou por difusão (onde não há movimento de fluido, somente o transporte de moléculas por difusão molecular). Sendo que o perfil de gradientes concentração difusivos já foi caracterizado, na literatura, como linear e estável através do monitoramento da intensidade de fluorescência (Atenciaet al. 2012). Estes gradientes 

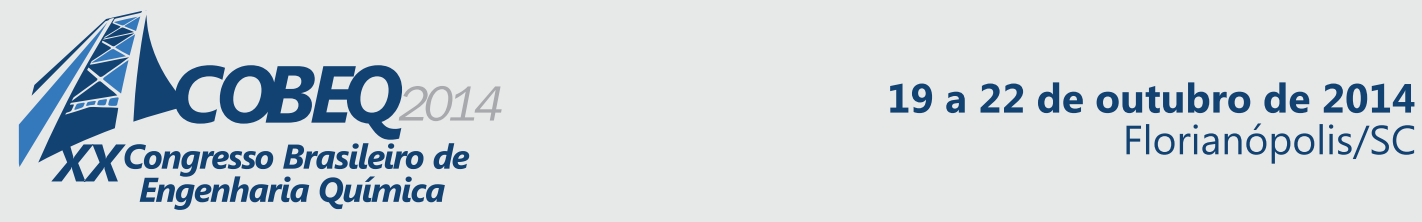

constituem uma ferramenta promissora para investigar o comportamento de células microbianas frente a diferentes concentrações de um determinado substrato.

No desenvolvimento de bioprocessos, a etapa inicial é uma das mais laboriosas e demanda de grandes quantidades de amostras, análises químicas e tempo (Kumar et al., 2004). Ainda, em tais ensaios há possíveis contaminações cruzadas e exigem de maior quantidade de energia devido ao tamanho dos equipamentos envolvidos (Kumar et al., 2004; Zhang et al., 2007; Au et al., 2011; Hegab et al., 2013). Assim, o desenvolvimento de bioprocessos pode ser otimizado com a utilização da microfluídica geradora de gradiente difusivo, podendo avaliar o crescimento celular frente a diferentes condições, realizar análises em tempo real por meio de sensores integrados, e obter resultados comparáveis aos processos convencionais, em um único dispositivo microfluídico (Hegab et al., 2013).Embora apresente um alto potencial investigativo, a microfluídica com geração de gradiente difusivo ainda é pouco explorada no campo da microbiologia industrial. A área de bioprocessos poderia se beneficiar com esta ferramenta, com destaque para as etapas de desenvolvimento, onde poderiam ser criadas técnicas para determinação de parâmetros cinéticos e seleção de condições fermentativas, minimizando tempo e custos operacionais.

Nesse contexto, este trabalho tem o objetivo investigar a aplicação desistemas microfluídicos geradores de gradiente de concentração difusivo em bioprocessos. Para isso, um dispositivo microfluídico gerador de gradiente de concentração difusivo já aplicado para células animais e aderentes foi adaptado para avaliar o crescimento microbiano de Saccharomyces cereviseae em diferentes concentrações de glicose, como substrato limitante, e em condição anaeróbia. Adicionalmente, comparou-se este crescimento celular com cultivo convencional em batelada e com isso, avaliar a aplicabilidade do dispositivo microfluídico como ferramenta no desenvolvimento de bioprocessos industriais.

\section{METODOLOGIA}

\subsection{Construção do Dispositivo Microfluídico com Gradiente de Concentração Difusivo}

O dispositivo microfluídico foi construído em vidro, com geometria baseada no trabalho de Atencia et al. (2012), composto por dois níveis. No nível inferior há a formação do gradiente difusivo e o crescimento celular eno nível superior é por onde escoam duas correntes de meio de cultura com de concentrações diferentes do substrato limitante. Os níveis inferior e superior se comunicam por portas laterais de acesso, que permitem o fluxo mássico difusivo de moléculas, sem ocorrer escoamento de fluído no nível inferior, conforme mostra a Figura 1.

O nível inferior do dispositivo foi construído por lamínula de vidro lisa e poli dimetilsiloxano (PDMS) laminado contendo a geometria dos três microcanais (microcâmaras) de dimensões 4x0,9x0,51mm, e também fez a aderência entre os vidros que compõe a base e topo dos microcanais. Estas microcâmaras no PDMS laminado foram desenhadas no software Corel draw® e criadas por ablação em máquina de laser de $\mathrm{CO}_{2}$ L-Solution 100 (Gravograph, USA), numa potência de 35 W. Já o nível superior construído com uma lamínula de vidro contendo os três pares de portas de 


\section{9 a 22 de outubro de 2014 \\ Florianópolis/SC}

acessos( 0,5 mm de diâmetro), feitos por processo de corrosão úmida e ajustando-se às extremidades das microcâmaras inferiores para não gerar diferença de pressão para entradas das soluções de concentrações distintas. Acima da lamínula com portas de acessos, colocou-se o PDMS laminado na geometria de canal em Y, por onde escoa as soluções. Fechou-se este microcanal superior com lâmina de vidro, a qual possui duas entradas e uma saída (1 mm de diâmetro, cada) feitos com Dremel® usando broca diamantada de $1 \mathrm{~mm}$ com rotação $3500 \mathrm{rpm}$. E, para servir de conexão para as mangueiras, foram colados nas bordas dos furos, pontas de ponteira de micropipeta (10 $\mu \mathrm{L})$ usando cola para vidro.

Após a construção do dispositivo microfluídico, foi avaliada a eficiência de selagem e a capacidade de gerar um perfil linear de gradiente através da intensidade de fluorescência dentro das microcâmaras, sendo imposto um gradiente de fluorescência usando Rodamina B a 0,1 $\mathrm{mM}$ (Sulforhodamine B sodium salt, Sigma-Aldrich) em uma das entradas e na outra, água destilada. Sendo que nas microcâmaras foi inserida somente água destilada, onde foi observado a formação e o tempo de estabilização do gradiente.

\subsection{Cultivo de Saccharomyces cerevesiae em Dispositivo Microfluídico}

Para os ensaios de crescimento microbiano no dispositivo microfluídico, a pré-adaptação da levedura $S$. cerevesiae ATCC 7754 foi realizada em meio de cultura YPD (Yeast-Peptone-Dextrose Agar $), \mathrm{pH} 5,0$, em agitação constante $(\sim 100 \mathrm{rpm})$ a $30^{\circ} \mathrm{C}$ por $24 \mathrm{~h}$. Após isto, fez-se a diluição seriada em solução tampão PBS (fosfato-salino) $\mathrm{pH}$ 6,0. Devido à escala micrométrica do sistema microfluídico, utilizou-se uma concentração celular de $\sim 0,5 \times 10^{2} \mathrm{cel} / \mu \mathrm{L}$. E, para comprovar a presença das células nas microcâmaras utilizou-se, em um dos ensaios, o reagente fluorescente FUN 1 numa concentração de $20 \mu \mathrm{M}$ do kit Live/Dead® Yeast Viability (Molecular Probes, Invitrogen).

Todas as peças e os acessórios do dispositivo microfluídico foram previamente lavados com detergente neutro e álcool $70 \%$ e esterilizados em radiação por luz UV por $1 \mathrm{~h}$. Montou-se o nível inferior do dispositivo microfluídico, fechando o microcanal inferior com a lamínula de vidro que contém as portas de acesso, e inoculou-se a suspensão celular através destes acesssos com auxílio de micropipeta com volume de $2 \mu \mathrm{L}$ e fechou-se o dispositivo microfluídico, como mostra a Figura 1. Estas etapas foram realizadas em capela de fluxo laminar.

Para impor a diferença de concentração de glicose utilizou-se duas soluções de meio YPD desgaseificados, $\mathrm{pH} 4,5$, variando apenas a concentração de glicose (substrato limitante, 0 e $40 \mathrm{~g} / \mathrm{L}$ ). Sendo que a quantidade de oxigênio remanescente foi desprezada e a conversão de glicose em etanol e gás carbônico não foi quantificada. Os meios foram inseridos através de seringas de 10 mL(Hamilton, USA) e operado em bomba tipo seringa (KD Scientific, USA), numa vazão de 15 $\mu \mathrm{L} / \mathrm{min}$ (Atencia et al., 2012), como mostrado na Figura 1.

O crescimento microbiano dentro das microcâmaras foi monitorado via microscópio confocal (Zeiss LSM780-NLO; Carl Zeiss AG, Germany) com temperatura controlada (PeconGmbH, Germany) a $30^{\circ} \mathrm{C}$. As imagens das três microcâmaras foram capturadas a cada 30 min, num período de 10 h e em condição anaeróbia. 
a)

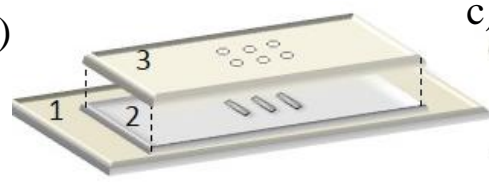

b)

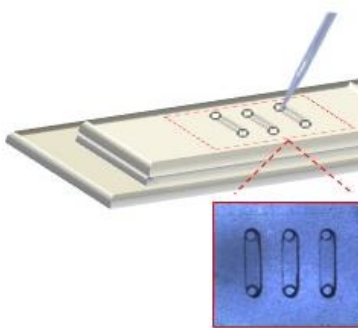

c)

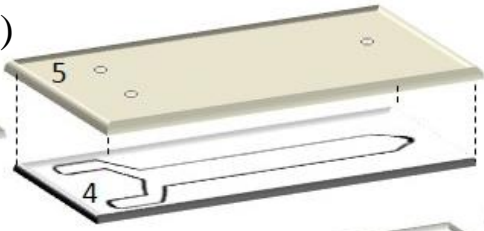

d)

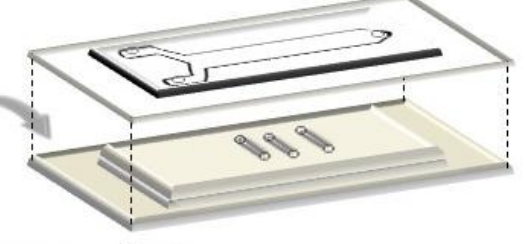

Microcâmaras: gradiente difusivo e crescimento celular e)

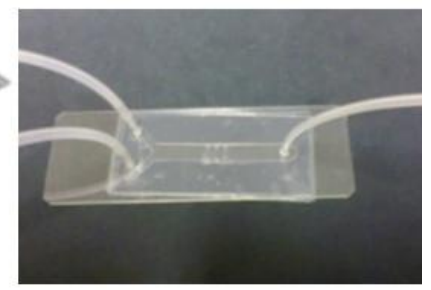

Figura 1 - Esquema da estrutura em dois níveis e montagem do dispositivo microfluídico com selagem por aderência do PDMS laminado: a) Nível inferior: formado por lamínula de vidro lisa (1) com PDMS laminado (2) e lamínula de vidro com portas de acesso laterais (3), b) inoculação da suspensão de células dentro das microcâmaras (nível inferior), onde ocorre o gradiente difusivo e crescimento celular, c) Nível superior: composto por PDMS laminado em canal (4) aderido à lâmina superior com duas entradas e uma saída (5) e, d) Fechamento: adesão da parte superior com a inferior do dispositivo; e) dispositivo microfluídico montado.

O comportamento da $S$. cerevisiaefoi observadoa partir das imagens com luz transmitida adquiridas ao longo do tempo(software ZEN 2012, Carl Zeiss AG, Germany), permitindo a contagem direta das células nas microcâmaras, nas quais foram feitas divisões em intervalos de 0,5 mm (subcâmaras) para avaliar o número de células referente a uma determinada faixa de concentração de glicose, como mostra a Figura 2. Para as análises foram excluídos os pontos extremos das microcâmaras porque não há geração de gradiente nestas regiões, uma vez que são as portas de acesso das correntes das soluções de concentrações diferentes de glicose as microcâmaras. Para indicar o gradiente de cada sub-câmara, correlacionou-se o ponto médio de distância da microcâmara com o as concentrações médias destas faixas.

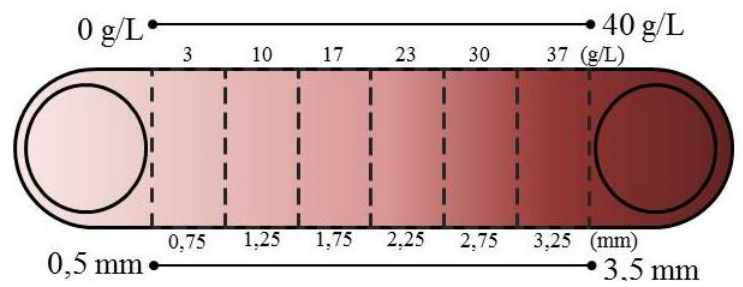

Figura 2 - Esquema da microcâmara com divisões $0,5 \mathrm{~mm}$ (sub-câmaras) para contagem de células em uma determinada faixa de concentração de glicose. 


\subsection{Fermentação em Batelada}

O cultivo em batelada foi realizado utilizando o mesmo meio YPD, $\mathrm{pH} 4,5$, variando apenas a concentração de glicose: 0 (controle), 10, 20, 30 e $40 \mathrm{~g} / \mathrm{L}$ de glicose, sendo usado $100 \mathrm{~mL}$ de meio em frascos Erlemmeyers e concentração inicial de $\sim 0,5 \times 10^{2}$ cel $/ \mu \mathrm{L}$. A fermentação foi conduzida a $30^{\circ}$ $\mathrm{C}$, por $10 \mathrm{~h}$ e agitação orbital constante de $100 \mathrm{rpm}$. Determinou-se a concentração celular através da leitura de absorbância $(600 \mathrm{~nm})$ a cada $1 \mathrm{~h}$ com o auxílio de curva de calibração por contagem em câmara de Neubauer.

\section{RESULTADOS E DISCUSSÃO}

O dispositivo construído em bases de vidro constituiu um sistema sem a interferência de gases nos microcanais, uma vez que o vidro é um material que não permite trocas gasosas, e como as soluções que escoaram neste dispositivo foram desgaseificadas, o ambiente foi considerado anaeróbio em todo o tempo de operação. Além disso, a selagem do dispositivo foi eficaz e capaz de formar um perfil gradiente de concentração linear e estável, como apresentado na Figura 3a.

Com base nisso, foi imposto uma diferença de concentração de glicose no dispositivo e o crescimento da levedura Saccharomyces cerevisiae ATCC 7754 foi monitorado, onde se observou o comportamento celular frenteao gradiente de 0 a $40 \mathrm{~g} / \mathrm{L}$ de glicose. A presença das células foi comprovada através de imagens obtidas utilizando sonda de fluorescência. No entanto, o crescimento celular foi avaliado sem fluorescência, para que não houvesse qualquer interferência. Neste caso, realizou-se a contagem direta das células nas sub-câmaras, correlacionando a posição dasmicrocâmaras com a concentração média de glicose em cada sub-câmara, gerando um gráfico do perfil de crescimento ao longo das microcâmaras, como apresenta a Figura 3.

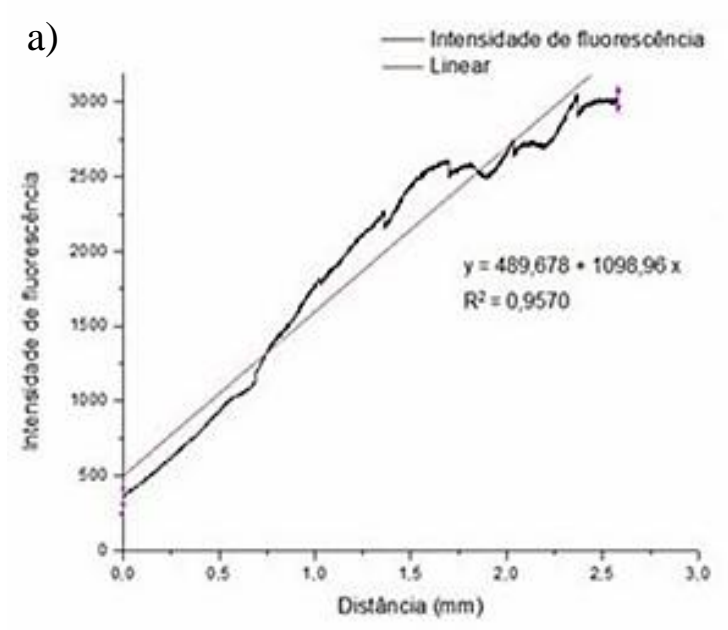

b)

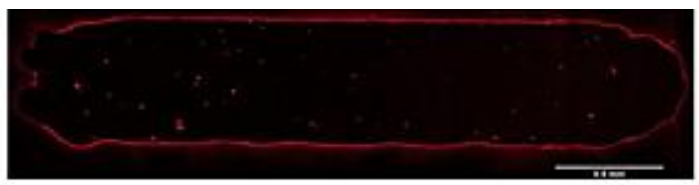

c)

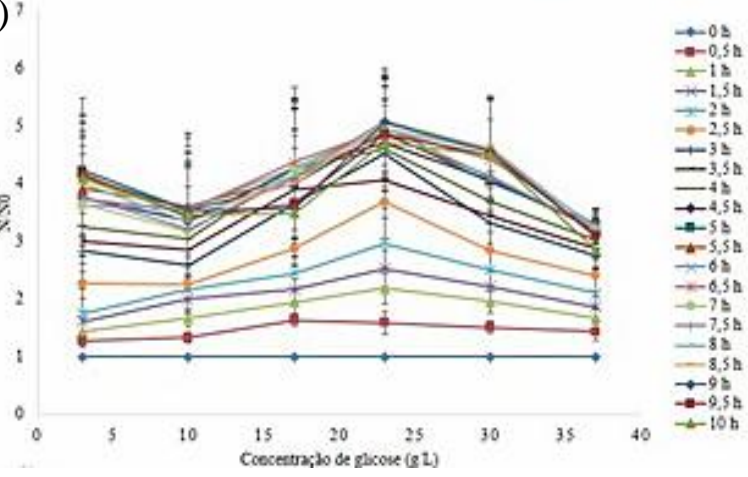

Figura 3 - Microfluídica e comportamento celular: a) perfil de gradiente linear observado pela intensidade de rodamina B $(0,1 \mathrm{mM})$, após $30 \mathrm{~min}$ de escoamento, b) presença da $S$. cerevisiae ATCC 7754 com fluorescência FUN $1(20 \mu \mathrm{M})$, c) perfis de crescimento da levedura ao longo do tempo e das microcâmaras $\left(\mathrm{N}_{0} \sim 0,5 \times 102 \mathrm{cel} / \mu \mathrm{L}\right)$. Barras de erros indicam o erro padrão das triplicatas. 


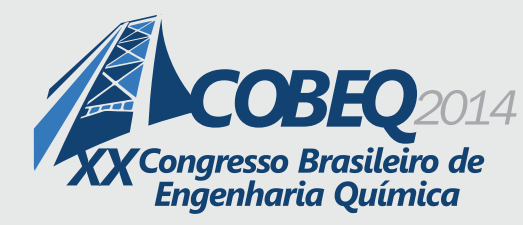

19 a 22 de outubro de 2014
Florianópolis/SC

A partir da Figura 3b, pode-se observar o aumento do número de células ao longo do tempo. Através do cultivo celular, notou-se que após 3 h houve maior número de células nas sub-câmaras referente na faixa de 23 a $30 \mathrm{~g} / \mathrm{L}$ de glicose e este comportamento se manteve constante ao longo das 10 h de observação. Nesta faixa de concentração o resultado observado foi correspondente ao esperado, uma vez que a concentração de glicose para o crescimento celular não deve ser maior do que $25 \%$ em massa, pois na fase inicial de crescimento a levedura utiliza a glicose para o seu metabolismo e um elevado teor deste açúcar eleva a pressão osmótica do meio (Sonnleitner \& Käppeli, 1986; Bai et al., 2008). Uma vez observado o crescimento celular no dispositivo microfluídico e tendo o número de células para cada sub-câmara, pode-se construir as curvas de crescimento microbiano ao longo do tempo para cada faixa de concentração de glicose, como apresenta a Figura 4a, permitindo a determinação da velocidade específica de crescimento da levedura nestas condições, como segue na Tabela 1. Como referência e para permitir a comparação do dispositivo microfluídico com um procedimento convencional, realizou-se uma série de cultivos em batelada (frascos Erlenmeyers), adotando as mesmas condições utilizadas no dispositivo microfluídico. Desta forma, pode-se também construir as curvas de crescimento microbiano pelo cultivo em batelada, como mostra Figura 4 b.
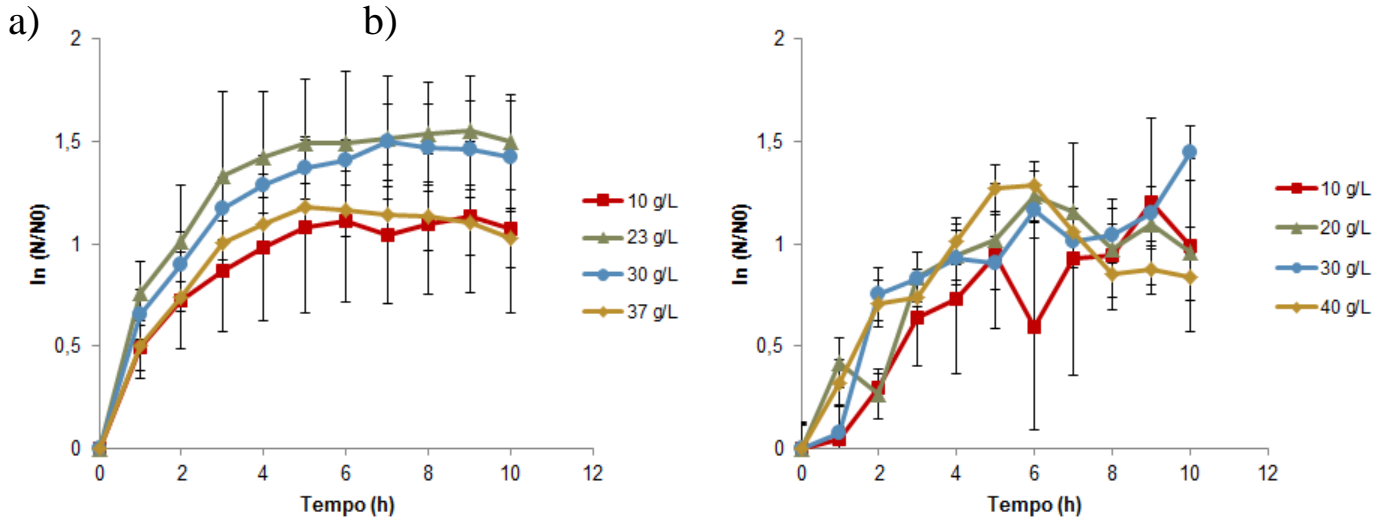

Figura 4 - Curvas de crescimento da $S$. cerevisiae ATCC 7754 em meios YPD (40 a 0 g/L de glicose) e $\mathrm{N}_{0} \sim 0,5 \times 10^{2} \mathrm{cel} / \mu \mathrm{L}$ : a) em dispositivo microfluídico baseado em gradiente de concentração difusivo b) cultivo convencional em batelada, sendo o meio YPD sem glicose apenas como controle, cujo $\ln$ $\left(\mathrm{N} / \mathrm{N}_{0}\right)$ manteve-se próximo a 0,5 . As barras de erros representam o erro padrão de triplicatas independentes.

Da mesma forma que observado no dispositivo microfluídico, como mostrado na Figura 4a, o perfil de crescimento com maior número de células ocorreu nas condições de 23 a $30 \mathrm{~g} / \mathrm{L}$ de glicose. No entanto, diferenças nos perfis de crescimento são esperadas na comparação entre cultivos em microfluídica e batelada. No caso microfluídico existe um fornecimento constante de substrato (injeção constante de meio de cultura) e no sistema batelada não há inserção de substrato durante o cultivo. Além disso, para viabilizar a contagem das células e não distorcer o gradiente de concentração, o número de células iniciais foi baixo $\left(0,5 \times 10^{2} \mathrm{cel} / \mu \mathrm{L}\right)$ o que pode prejudicar o cultivo em batelada $(100 \mathrm{~mL})$, gerando maiores oscilações ao longo do tempo. 
A partir das curvas de crescimento microbianas foram determinadas as velocidades específicas de crescimento máximas da levedura em dispositivo microfluídico $\left(\mu_{\mathrm{x}(\mathrm{M})}\right)$ e cultivo em batelada convencional $\left(\mu_{\mathrm{x}(\mathrm{B})}\right)$, como mostra a Tabela 1 .

Tabela 1 - Velocidade específica de crescimento máxima da $S$. cerevisiae ATCC 7754 cultivado em dispositivo microfluídico com gradiente de concentração $\left(\mu_{\mathrm{x}(\mathrm{M})}\right)$ e cultivo convencional em batelada

$\left(\mu_{\mathrm{x}(\mathrm{B})}\right)$.

\begin{tabular}{|c|c|c|c|}
\hline \multicolumn{2}{|c|}{$\begin{array}{c}\text { DISPOSITIVO } \\
\text { MICROFLUIDICO }\end{array}$} & \multicolumn{2}{|c|}{$\begin{array}{c}\text { CULTIVO CONVENCIONAI } \\
\text { EM BATELADA }\end{array}$} \\
\hline Glicose $(\mathrm{g} / \mathrm{L})$ & $\mu_{\mathrm{x}(\mathrm{M})} \pm \mathrm{DP}\left(\mathrm{h}^{-1}\right)$ & $\begin{array}{c}\text { Glicose } \\
(\mathrm{g} / \mathrm{L})\end{array}$ & $\mu_{\mathrm{x}(\mathrm{B})} \pm \mathrm{DP}\left(\mathrm{h}^{-1}\right)$ \\
\hline $\begin{array}{c}3 \\
10\end{array}$ & $\begin{array}{l}0,17 \pm 0,12 \\
0,20 \pm 0,17\end{array}$ & 10 & $0,21 \pm 0,23$ \\
\hline $\begin{array}{l}16 \\
23\end{array}$ & $\begin{array}{l}0,24 \pm 0,19 \\
0,24 \pm 0,14\end{array}$ & 20 & $0,24 \pm 0,16$ \\
\hline 30 & $0,24 \pm 0,02$ & 30 & $0,21 \pm 0,01$ \\
\hline 36 & $0,20 \pm 0,07$ & 40 & $0,19 \pm 0,05$ \\
\hline
\end{tabular}

p > 0,01: não há diferença estatisticamente significativa entre as médias das velocidades específicas de crescimento obtidas entre sistemas microfluídica e cultivo em batelada. DP: Desvio padrão de triplicatas.

A partir da Tabela 1, observou-se que não houve diferença estatisticamente significativa entre as médias das velocidades específicas de crescimento para dispositivo microfluídico e o cultivo em batelada, tendo ambos conduzidos com concentrações celulares baixas e com faixas de concentração de glicose suficientes para sustentar o crescimento microbiano. Os erros elevados associados às velocidades específicas de crescimento são explicados pelo monitoramento via contagem celular, avaliação inevitável devido à dificuldade de manutenção da quantidade de inóculo nos ensaios nas diferentes escalas.

Valores similares de $\mu_{\mathrm{x}}\left(0,21 \pm 0,01 \mathrm{~h}^{-1}\right)$ foram obtidos por Taherzadeh et al. (1997) utilizando cultivo de $S$. cerevisiae com glicose a $30 \mathrm{~g} / \mathrm{L}$, para cultivo em batelada. Enquanto que Aibaet al., (1976) obtiveram um $\mu \mathrm{x}=0,24 \mathrm{~h}^{-1}$ em batelada alimentada ( $S$. cerevisiae), utilizando uma concentração inicial de $20 \mathrm{~g} / \mathrm{L}$ de glicose. Neste último caso, a diferença entre a batelada alimentada e dispositivo microfluídico é que na batelada alimentada não há variação de substrato pelo consumo, e tal característica é semelhante à condição da microfluídica, porém na batelada alimentada não há variação de células devido à taxa de diluição.

A comparação de $\mu_{\mathrm{x}}$ do dispositivo microfluídico com o cultivo em batelada e batelada alimentada indica a viabilidade da avaliação o crescimento microbiano, uma vez que este parâmetro cinético foram comparáveis ao cultivo convencional. No entanto, com o dispositivo microfluídico,houve menor consumo de reagentes, além de permitir facilmente explorar outras faixas de concentração ou o efeito de outros substratos limitantes. Sendo possível a obtenção de resultados mais rápidos do que as técnicas convencionas, possibilitando a otimização das etapas investigativas de bioprocessos a partir de dispositivo gerador de gradiente difusivo. 


\section{CONCLUSÃO}

O dispositivo microfluídico investigado foi capaz de gerar um gradiente de concentração linear e viabilizar a obtenção da velocidade máxima de crescimento celular para células livres. Este tipo de sistema microfluídico pode ser considerado uma ferramenta com potencial para investigação de comportamento celular para utilização durante a etapa de desenvolvimento de bioprocessos com aplicação industrial.

\section{REFERÊNCIAS}

AIBA, S.; NAGAI, S.; NISHIZAWA, Y. Fed batch culture of Saccharomyces cerevisiae: A perspective of computer control to enhance the productivity in baker's yeast cultivation. Biotechnol. Bioeng.,v. 18, p. 1001-1016, 1976.

ATENCIA, J.; COOKSEY, G. A.; LOCASCIO, L. E. A robust diffusion-based gradient generator for dynamic cell assays.Lab Chip, v. 12, p. 309-316, 2012.

AU, S. H.; SHIH, S. C.; WHEELER, A. R. Integrated microbioreactor for culture and analysis of bacteria, algae and yeast. Biomed. Microdevices, v. 13, p. 41-50, 2011.

BAI, F.; ANDERSON, W.; MOO-YOUNG, M. Ethanol fermentation technologies from sugar and starch feedstocks. Biotechnol. Adv.,v. 26, p. 89-105, 2008.

HEGAB, H. M.; ELMEKAWY, A.; STAKENBORG, T. Review of microfluidic microbioreactor technology for high-throughput submerged microbiological cultivation.Biomicrofluidics, v. 7, p. 021502, 2013.

KUMAR, S.; WITTMANN, C.; HEINZLE, E. Review: minibioreactors. Biotechnol. Lett., v. 26, p. 1$10,2004$.

SCHAPPER, D.; ALAM, M.N.H.; SZITA, N.; LANTZ, A.E.; GERNAEY, K.V. Application of microbioreactors in fermentation process development: a review. Anal. Bioanal. Chem., v. 395, p. 679-695, 2009.

SONNLEITNER, B.; KÄPPELI, O. Growth of Saccharomyces cerevisiae is controlled by its limited respiratory capacity: Formulation and verification of a hypothesis. Biotechnol. Bioeng., v. 28, p. 927-937, 1986.

TAHERZADEH, M. J.; NIKLASSON, C.; LIDÉN, G. Acetic acid-friend or foe in anaerobic batch conversion of glucose to ethanol by Saccharomyces cerevisiae? Chem. Eng. Sci.,v. 52, p. 26532659, 1997.

TAVANA, H.; CHUNG, Y. K.; KUO, C. H.; TAKAYAMA, S. Microfluidic Systems for Cellular Applications. In: TIAN, W.C.; FINEHOUT, E. Microfluidics for biological applications. New York: Springer Science, 2008.

WHITESIDES, G. M. The origins and the future of microfluidics.Nature, v. 442, p. 368 - 373, 2006.

ZHANG, Z.; PEROZZIELLO, G.; BOCCAZZI, P.; SINSKEY, A. J.; GESCHKE, O.; JENSEN, K. F. Microbioreactors for bioprocess development. J. Lab. Autom., v. 12, p. 143-151, 2007. 